\title{
Localization of the bregma and its clinical relevance
}

\author{
Bilgehan Solmaz \\ Department of Neurosurgery, Istanbul Education and Research Hospital, Istanbul, Turkey
}

\begin{abstract}
Objectives: External landmarks on the skull are important guides in various neurosurgical procedures. The localization of the bregma is vitally important in bedside ventriculostomy and craniotomies. The aim of the current study was to verify the localization of the bregma.

Methods: This was performed on dry skulls $(n=72)$ and sagittal computerized tomography (CT) images of patients $(n=100)$. The age and the sex of dry skulls were unknown. Of the 100 patients, 48 were males and 52 were females and the mean age for males was 51.14 and for females was 55.34. The distance between nasion to inion and nasion to bregma were measured from both dry skulls and on multiplanar reformation (MPR) sagittal images. The ratio of the two measurements was calculated.

Results: The nasion to bregma distances on 72 dry skulls ranged between 120-140 mm: the average distance was $124.3 \pm 6.9 \mathrm{~mm}$. The nasion to inion distance ranged between $295-345 \mathrm{~mm}$; the average was $320.8 \pm 14.4 \mathrm{~mm}$. The ratio of nasion to bregma distance to nasion to inion distance was calculated as 0.384 . The nasion to bregma distance obtained from 100 CT images scans ranged from 107 to $139 \mathrm{~mm}$ (average 126.6 7.3 ) $\mathrm{mm}$. The nasion to inion distances ranged between 301 and 356 (average 330.2 \pm 15.2 ) mm. The ratio of nasion to bregma distance to nasion to inion distance was calculated as 0.383 . Measurements for females were lower than males, but there was no statistical significance between genders. The multiplication of the nasion to inion distance by 0.38 gave the location of bregma for both genders.

Conclusion: An accurate and reliable ratio (0.38 times the distance from nasion to inion) was obtained to define the bregma. The coronal suture lay on each side of bregma, so knowing the exact localization of bregma and of the coronal suture can be vitally important in various surgical procedures to the cranium.
\end{abstract}

Keywords: coronal suture; craniotomy; external landmark; ventriculostomy

Anatomy 2018;12(3):135-139 (2018 Turkish Society of Anatomy and Clinical Anatomy (TSACA)

\section{Introduction}

The bregma, an external promontory on the skull, is an important bony landmark for various neurosurgical interventions such as bedside ventriculostomy and various craniotomies. The coronal suture lateral to the bregma on each side is used as guide to reach the precentral and postcentral gyri and the central sulcus. Therefore, for preoperative and intraoperative localization of the relevant cortical areas, the bony superficial landmarks are of utmost importance. Additionally, a frontal burr hole (Kocher's point) is made anterior to the coronal suture to approach the lateral ventricle and avoid the motor strip. Empirical methods such as finger pad palpation have been used in localizing the bregma and the coronal suture.
This anatomical study aimed to verify the exact localization of the bregma and the coronal suture using dry skulls and computerized tomography (CT). Newer imaging techniques and improved technology such as navigation systems can demonstrate fine details of the region. Although more than 2,000 medical facilities world-wide utilize these systems, many institutions do not have this technological capacity, ${ }^{[1]}$ and in such situations it is valuable to have fine anatomical knowledge of the localization of the bregma as well as the coronal suture.

\section{Materials and Methods}

The measurements were obtained from dry skulls and from sagittal CT images. A total of seventy-two adult skulls of 

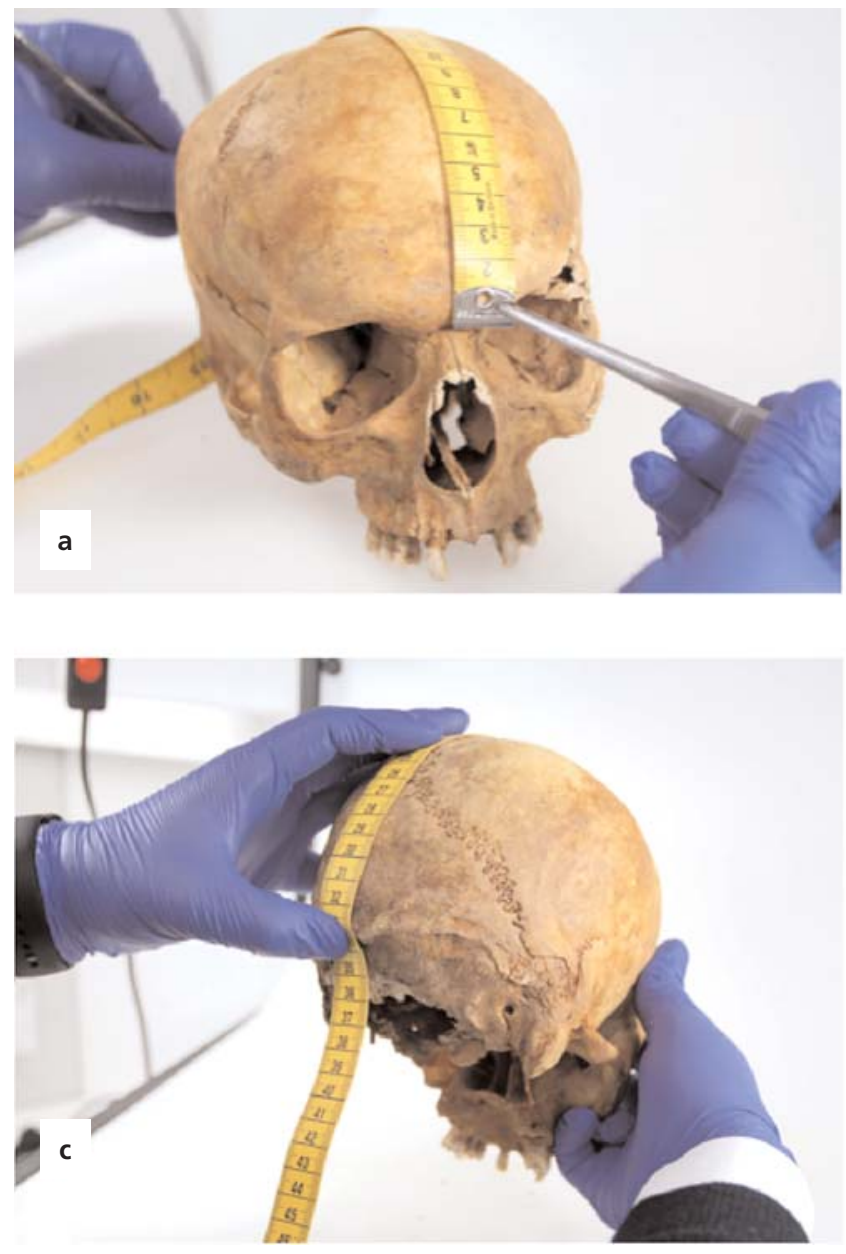

unknown age and gender were obtained from the Laboratory of Human Anatomy, Istanbul University School of Dentistry, Istanbul, Turkey. The CT images were obtained from patients who underwent CT angiography for a suspicion of a ruptured aneurysm at the Department of Neurosurgery of Marmara University, Istanbul, Turkey, from January 2012 to December 2014. Of the 100 patients, 48 were males and 52 were females, and the mean age was 53.39 (range 18-85) years.

Three anatomical landmarks on the outer surface of the dry skull were defined: nasion (intersection of the frontal bone and two nasal bones), bregma (intersection of the coronal suture and the sagittal suture), and inion (the highest point of the external occipital protuberance). The distance between nasion-inion and nasion-bregma were measured using a tape measure (Figure 1). The same measurements were repeated in two-dimensional (2D) multiplanar reformation (MPR) sagittal images with simultaneous correlation of coronal and axial plane CT images by using the Philips IntelliSpace Portal (v5.0.2.40009; Philips Healthcare, Cleveland, OH, USA) software (Figure 2).

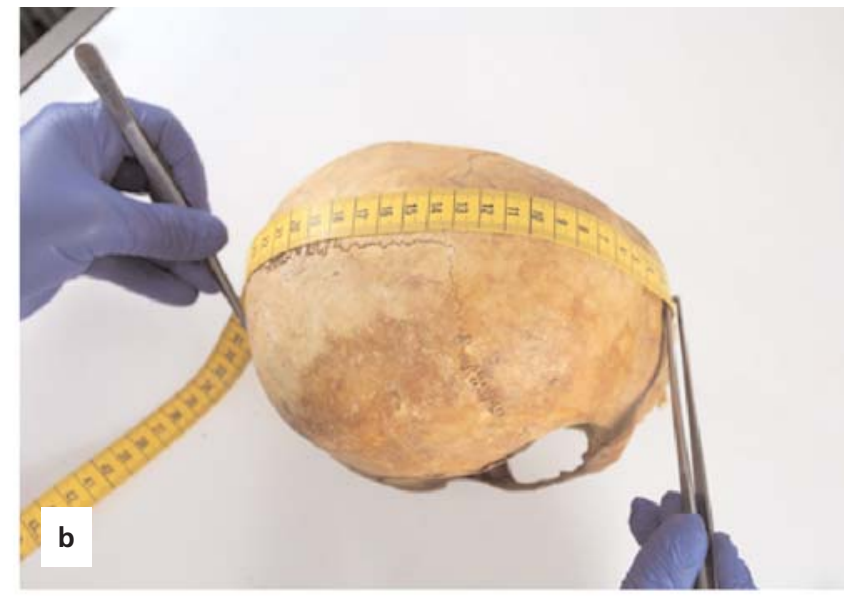

Figure 1. Samples of the measurements made on a dry skull. (a, b) The distance between nasion (intersection of the frontal bone and two nasal bones) and bregma (intersection of the coronal suture and the sagittal suture). (c) The distance between nasion and inion (the highest point of the external occipital protuberance). [Color figure can be viewed in the online issue, which is available at www.anatomy.org.tr]

Independent t-test was used to compare means of two groups. Data analysis was done with using SPSS Version 21.0 statistical software (SPSS Inc., Chicago, IL, USA).

\section{Results}

The nasion to bregma distance obtained from 72 dry skulls ranged between 120 and $140 \mathrm{~mm}$ and the average measurement was $124.3 \pm 6.9 \mathrm{~mm}$. The nasion to inion distance ranged between 295-345 (average 320.8×14.5) mm (Table 1). The ratio of nasion to bregma distance to nasion to inion distance was calculated as 0.384 .

The nasion to bregma distance obtained from $100 \mathrm{CT}$ images ranged between 107-139 (average 126.6 \pm 7.3 ) mm. The nasion to inion distance ranged between 301-356 (average $330.2 \pm 15.2$ ) $\mathrm{mm}$ (Table 1). The ratio of nasion to bregma distance to nasion to inion distance was calculated as 0.383 . No statistically significant difference was present between two groups regarding either the nasion to bregma and nasion to inion measurements or the ratio between two groups $(\mathrm{p}<0.05)$. 

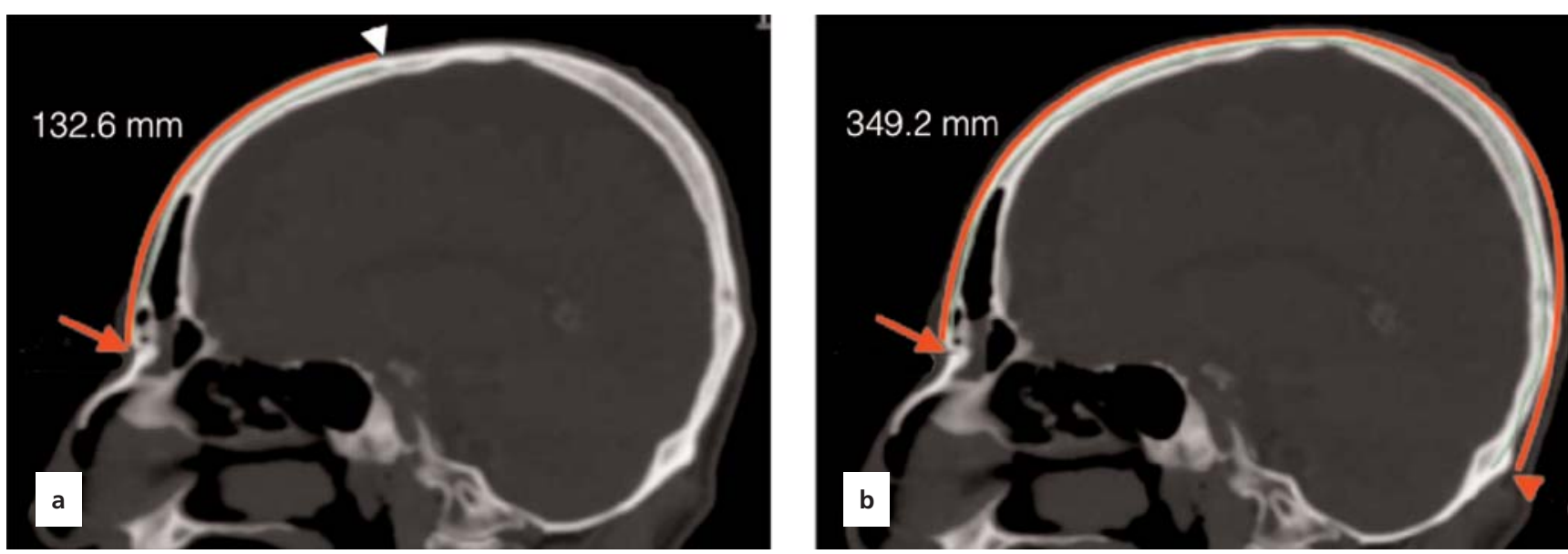

Figure 2. Samples of measurements made on sagittal computerized tomography (CT) images of the patients. (a) The distance between nasion (red arrow) and bregma (white arrowhead). (b) The distance between nasion and inion (red arrowhead). [Color figure can be viewed in the online issue, which is available at www.anatomy.org.tr]

\section{Discussion}

The bregma and the coronal suture are important bony landmarks on the skull. Empiric methods are used to localize these structures. In the present study, we developed an accurate and reliable ratio ( 0.38 times of the distance between the nasion to inion) which determined the location of bregma and also of coronal suture situated lateral to bregma. The cranial sutures connecting the flat bones of the neurocranium are derived from neural crest cells and paraxial mesoderm. The single coronal suture is one of the synarthroses comprising the cranial vault, separating the frontal from the parietal bones. The coronal suture was first described by Avicenna in his Canon (alQanun fi'l-Tibb) as "an arc in whose center a perpendicular line has been set up". In the early half of 11 th century, William of Saliceto, a prominent surgeon of 13th century, used the term "coronal suture" for the first time. ${ }^{[2]}$

Numerous craniometric methods have been described to define the location of the central sulcus and the motor cortex. ${ }^{[3-10]}$ Additionally, there are studies which have shown the relation between the coronal suture and central sulcus. However, there are few morphometric studies related to the bregma junction itself. ${ }^{[1]}$ In the literature, the average distance between the nasion to bregma was reported as $126.6 \mathrm{~mm}$ on CT. In the present study, we measured this distance as $124.3 \pm 6.9 \mathrm{~mm}$ on dry skulls and $126.6 \pm 7.3 \mathrm{~mm}$ on CT. Our CT measurements were exactly the same with the former study; however, dry skull measurements were slightly lower than the CT measurements. ${ }^{[12]}$ The only other study that defined the location of the bregma in terms of a ratio was by Anderson and Makins in $1889 .{ }^{[13]}$ They defined the bregma as two-fifths of the length of nasion to inion (0.4 ratio $)$ and in accordance with our ratio $(0.38 \approx 2 / 5$ nasion to inion).

The bregma and the coronal suture are frequently used as landmarks since they can be easily recognized radiologically and palpated subcutaneously. However, sometimes it can be a challenge to palpate these structures, particularly if not performed by experienced hands. In cases when coronal suture is partly or completely synostotic, it is almost impossible to palpate. With the 0.38 ratio we

Table 1

Descriptive statistics of continuous data.

\begin{tabular}{lccc}
\hline & $\begin{array}{c}\text { Dry skulls } \\
(\mathbf{n = 7 2 )}\end{array}$ & $\begin{array}{c}\text { CT (male+female) } \\
(\mathbf{n = 1 0 2})\end{array}$ & p-value \\
\hline Nasion-bregma distance mean $\pm \mathrm{SD}(\mathrm{mm})$ & $124.3 \pm 6.9$ & $126.6 \pm 7.3$ & $<0.001$ \\
Nasion-inion distance mean $\pm \mathrm{SD}(\mathrm{mm})$ & $320.8 \pm 14.4$ & $330.2 \pm 15.2$ & $<0.001$ \\
Ratio Nasion-bregma/Nasion-inion & 0.384 & 0.383 & $<0.001$ \\
\hline
\end{tabular}

$\mathrm{n}$ : sample count; SD: standard deviation. 
suggest, bregma can be midsagittally localized easily with a negligible error.

The coronal suture lies on each side of the bregma but the coronal suture does not extend perpendicular to the midline. Chen et al ${ }^{[14]}$ stated that the distance to this perpendicular line; that is, the coronal plane from the coronal suture gradually increases with distance from the bregma. In the same way, the central sulcus and the precentral gyrus bow forward as they pass from the midline. Ebeling et al ${ }^{[15]}$ described the localization of the coronal suture relative to the precentral gyrus being highly variable. Kendir et al. ${ }^{[16]}$ reported that the precentral gyrus was located approximately $4.5 \mathrm{~cm}$ and the postcentral gyrus was located approximately $6.5 \mathrm{~cm}$ behind the bregma on the midline. Rivet et al. ${ }^{[17]}$ stated that the distance from the coronal suture to the motor cortex was $<3 \mathrm{~cm}$ in children under 6 years. Sarmento et al ${ }^{[18]}$ stated that the distance between the coronal suture and the central sulcus ranged from 5 to $6.6 \mathrm{~cm}$, in accordance to measurements of Gusmão et al. ${ }^{[11]}$ and Ribas et al ${ }^{[12]}$ in the adult. Further, Frigeri et al. ${ }^{[19]}$ reported that the precentral gyrus and central sulcus are closest at a point near where the superior temporal line crossed the coronal suture. Further, at this point all the branches of the middle meningeal artery ran posterior to the coronal suture. Therefore, the location of bregma and coronal suture is used as an important guide during preoperative surgical planning.

The bregma point and croronal suture are important bony landmarks for various neurosurgical procedures such as external ventricular drainage (EVD) placement, endoscopic third ventriculostomy (ETV) and craniotomy. ${ }^{[20]}$ Amongst them, EVD placement is one of the most common emergent and life-saving procedures in neurosurgery practice. For this purpose, freehand pass technique is frequently performed at the bedside by young neurosurgeon trainees. Ventricular catheter is inserted from a frontal burrhole toward the ipsilateral frontal horn of the lateral ventricle. Kocher's point is a common burrhole point that is located $2.5 \mathrm{~cm}$ from midline and $1 \mathrm{~cm}$ anterior to the coronal suture. ETV is increasingly used as a treatment of choice in various forms of hydrocephalus, particularly those of obstructive types. The entry point and thereby optimal trajectory are crucial to achieve into the third ventricle floor. Similarly, the coronal suture and bregma point are used to estimate the entry point for ETV.

Sutures are primary sites of osteogenesis mediating much of the growth of the skull instead of simple articulations between bones. The coronal suture provides sagittal growth of the skull. A significant increase, from childhood to adolescence, is expected in the length of the cranial vault. An interruption during cranial growth may result in premature ossification. The author of the present study is aware that suture morphogenesis is a highly complex process produced by multiple factors and their interactions cannot be established on a single algorithm. Even so, since the relationship between the cranial dimensions and sutural complexity plays a prominent role in the development of the adult cranium, there may be a developmental anomaly if the suggested ratio $(0.38)$ does not fit.

In the present study, we specified a ratio which is the quantification of a multiplicative relationship, and thus provided a more accurate number representing the detailed topography. Further, giving a ratio can take individual variations into consideration.

\section{Conclusion}

Despite the advancements in intraoperative image guided systems, information on constant landmarks such as bregma, inion and nasion points continue to be indispensable for the neurosurgeon. Therefore, localization of the eloquent cortical areas based on superficial landmarks is of utmost importance in cranitomy procedures.

\section{References}

1. Basarslan SK, Göcmez C. Neuronavigation: a revolutionary step of neurosurgery and its education. The Medical Journal of Mustafa Kemal University 2014;17:24-31.

2. Di Leva A, Brunner E, Davidson J, Pisano P, Haider T, Stone SS, Cusimano MD, Tschabitscher M, Grizzi F. Cranial sutures: a multidisciplinary review. Childs Nerv Syst 29:2013;893-905.

3. Broca P. Sur le principe des localisations cérébrales. Bull Soc d'Anth II 1861;190-204.

4. DaCosta JC, Spitzka EA. Anatomy, descriptive and surgical: Henry Gray. 17th. ed. Philadelphia (PA): Lea \& Febiger; 1908. p. 970.

5. Kido DK, LeMay M, Levinson AW, Benson WE. Computed tomographic localization of the precentral gyrus. Radiology 1980;135: 373-7.

6. Martin N, Grafton S, Viñuela F, Dion J, Duckwiler G, Mazziotta J, Lufkin R, Becker D. Imaging techniques for cortical functional localization. Clin Neurosurg 1992;38:132-65.

7. Rhoton AL Jr. The cerebrum. Neurosurgery 2002:51:S1-51.

8. Schultze OMS, Steward GD: Atlas and textbook of topographic and applied anatomy. Philadelphia (PA): WB Saunders; 1905. p. 37.

9. Taylor AJ, Haughton VM, Syvertsen A, Ho KC. Taylor-Haughton line revisited. AJNR Am J Neuroradiol 1980;1:55-6.

10. Wilkins RH, Rengachary SS (editors). Neurosurgery. New York (NY): McGraw-Hill; 1985. p. 3633-43.

11. Gusmão S, Reis C, Silveira RL, Cabral G. Relationships between the coronal suture and the sulci of the lateral convexity of the frontal lobe: neurosurgical applications. Arq Neuropsiquiatr 2001;59:570-6.

12. Ribas GC, Yasuda A, Ribas EC, Nishikuni K, Rodrigues AJ Jr. Surgical anatomy of microneurosurgical sulcal key points. Neurosurgery 2006;59:177-210. 
13. Anderson W, Makins GH. Experiments in cranio-cerebral topography. J Anat Physiol 1889;23:455-65.

14. Chen F, Chen T, Nakaji P. Adjustment of the endoscopic third ventriculostomy entry point based on the anatomical relationship between coronal and sagittal sutures. J Neurosurg 2013;118:5103.

15. Ebeling U, Rikli D, Huber P, Reulen HJ. The coronal suture, a useful bony landmark in neurosurgery? Craniocerebral topography between bony landmarks on the skull and the brain. Acta Neurochir (Wien) 1987;89:130-4.

16. Kendir S, Acar HI, Comert A, Ozdemir M, Kahilogullari G, Elhan A, Ugur HC. Window anatomy for neurosurgical approaches. Laboratory investigation. J Neurosurg 2009;111:365-70.

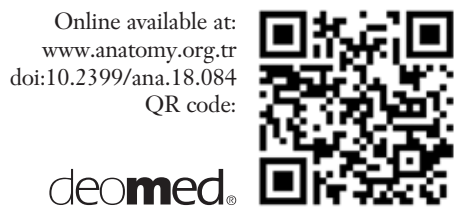

17. Rivet DJ, O'Brien DF, Park TS, Ojemann JG. Distance of the motor cortex from the coronal suture as a function of age. Pediatr Neurosurg 40:2004;215-9.

18. Sarmento SA, Jácome DC, de Andrade EM, Melo AV, de Oliveira OR, Tedeschi H. Relationship between the coronal suture and the central lobe: how important is it and how can we use it in surgical planning? Arq Neuropsiquiatr 2008;66:868-71.

19. Frigeri T, Paglioli E, de Oliveira E, Rhoton AL Jr. Microsurgical anatomy of the central lobe. J Neurosurg 122:2015;483-98.

20. Tubbs RS, Loukas M, Shoja MM, Bellew MP, Cohen-Gadol AA. Surface landmarks for the junction between the transverse and sigmoid sinuses: application of the "strategic" burr hole for suboccipital craniotomy. Neurosurgery 2009;65:37-41.

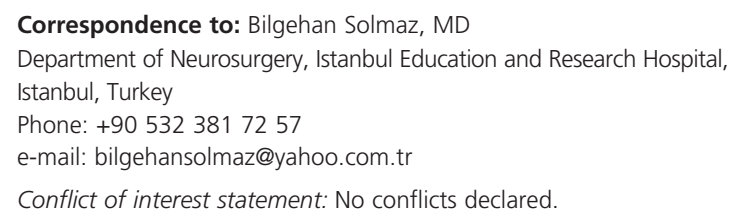

This is an open access article distributed under the terms of the Creative Commons Attribution-NonCommercial-NoDerivs 3.0 Unported (CC BY-NCND3.0) Licence (http://creativecommons.org/licenses/by-nc-nd/3.0/) which permits unrestricted noncommercial use, distribution, and reproduction in any medium, provided the original work is properly cited. Please cite this article as: Solmaz B. Localization of the bregma and its clinical relevance. Anatomy 2018;12(3):135-139. 